\title{
Reconstructive and reproductive models of memory
}

\author{
JOHN F. HALL \\ Pennsylvania State University, University Park, Pennsylvania
}

\begin{abstract}
The adequacy of reconstructive and reproductive models of memory has been in dispute ever since Bartlett's (1932) publication of his volume Remembering. Experimental as well as anecdotal evidence suggests that neither model can adequately account for all of the findings. We would suggest that to be adequate, an explanation of verbal memory should focus on a memory classification based on behavioral measures. Thus, it is suggested that verbal memory consists of at least two basic types of remembered material: (1) verbatim memory and (2) memory for gist. The latter category involves a frequently encountered process that we have identified as abstractive congruence; a reconstructive process, abstractive incongruence, is also found, but it is found much less frequently.
\end{abstract}

The position taken by British empiricist philosophers that memory consisted of a reproduction or a faded copy of the individual's sensory experience was for some time either explicitly (or tacitly) accepted by many 20th-century psychologists interested in verbal learning and memory. It is not surprising that this should be the case. Beginning with Ebbinghaus (1885/1913), list learning served as a basic verbal learning task for many experimenters, and the subject's overt responses in such tasks were generally identical to the presented material, thus suggesting that the memory of the sensory experience arising from learning the list faithfully represented the items that had been presented.

In 1932, however, Bartlett proposed an alternative to the reproductive model of memory. In his volume Remembering, he analyzed a series of protocols in which subjects attempted to recall a previously read narrative entitled The War of the Ghosts. Bartlett discovered pervasive inaccuracies in recall, with his subjects (1) omitting much of what had been originally presented, as well as (2) frequently providing a radical transformation of the original material. These behavioral changes and transformations were identified by Bartlett as involving the memorial processes of (1) abstraction and (2) reconstruction (or construction).

In addition, Bartlett (1932) also introduced the concept of the schema. Here he proposed that our knowledge (or memory) of the world comprised sets of models, or schemata, derived from our past experiences. New material that was to be learned, such as the prose that Bartlett had used as his experimental material, was integrated by the subject into the schema. If the new material was in conflict with the schema, reconstruction changed the memorial representation in such a way as to provide consistency. ${ }^{1}$

Correspondence may be addressed to John F. Hall, Department of Psychology, 417 Bruce V. Moore Building, Pennsylvania State University, University Park, PA 16802.
From this analysis, Bartlett was led to describe remembering as "an imaginative reconstruction, or construction, built out of the relation of our attitude towards a whole active mass of organized past reactions or experiences. It is thus hardly ever really exact, even in the most rudimentary cases of rote recapitulation, and it is not all important that it should be" (p. 213).

Bartlett's writing was as much an attack on a reproductive model of memory as it was a speculative description of what he perceived to be the nature of remembering. However, his experiments and speculation did not strike a responsive chord among most investigators in the United States, in particular among the functionalists, whose experimental studies in verbal learning and retention had continued in the Ebbinghaus tradition. McGeoch (1933), for example, in his review of Bartlett's volume, wrote that "the experiments which this book reports are outside the current of contemporary American research upon memory," although he did acknowledge Bartlett's experiments to be "of sufficient importance to make a current of their own" (p. 774).

By the early sixties, however, there was a growing disillusionment among investigators with regard to both list learning tasks and the learning principles that had been generated from their use. It was suggested that learning and memory tasks should employ prose rather than lists of isolated words and/or nonsense syllables; in fact, nonsense-syllable learning was described by some as being the epitome of psychological irrelevance. Moreover, the learning "principles" arising from the many experiments conducted during this period were considered to have little significance for a basic understanding of human memory. Tulving and Madigan (1970) wrote that "nothing very much has changed over the past hundred years in the understanding of how people learn and remember things," and that "the broad picture we have of human memory in 1970 does not differ from that in 1870"' (pp. 476-477). This disenchantment was accom- 
panied by the emergence of the information-processing position stemming from Wiener's (1948) work in cybernetics, and from the development of the computer, which provided the memory constructs of encoding, storage, and retrieval. It is not surprising that Bartlett's (1932) early experiments using prose and the posited processes of abstraction and reconstruction assumed belated importance among psychologists interested in the examination of memory.

The process of abstraction has generated some interest among experimenters, beginning with the work of Gomulicki (1956) and continuing with studies by Johnson (1970, 1974), Meyer and McConkie (1973), Rummelhart (1976), and Schultz and Johnson (1982). Bartlett's postulation of reconstruction, however, which was hypothesized to be the foundation of memory, aroused the greater attention among investigators. One contemporary advocate of this point of view was Neisser (1967), who in his volume Cognitive Psychology argued that the faded copy (or reproductive) model of memory, or what he termed the reappearance hypothesis, was not viable. Neisser pointed out that if reappearance really was the governing principle of mental life, "the repetition of earlier acts or thoughts should be the natural way of responding and variation the exception." The opposite, however, was true: "Precise repetition of any movement, any spoken sentence, or any consequence of thought is extremely difficult to achieve. When repetition does occur, as in dramatic acting or nonsense syllable learning, or a compulsive sequence of actions, we ascribe it either to long, highly motivated practice or to neurotic defensiveness" (p. 282). ${ }^{2}$

Only recently, Neisser $(1982,1984)$ has reaffirmed his position, writing that the reappearance hypothesis is surely wrong and that modern cognitive psychology has found many reasons to prefer Bartlett's (1932) reconstruction position. Constructive recall, Neisser (1984) has posited, is the rule, whereas literal recall is the exception. Continuing, he has suggested "that remembering is like problem solving rather than like reproduction. People use their general knowledge to answer even very specific recall questions. The widely held belief in permanent storage of specific experiences has essentially no basis in fact"' (p. 33).

Neisser's advocacy of Bartlett's reconstructive model has been, at least in part, responsible for many investigators examining the nature of the mental representation that arises from the learning of prose. Bransford and Franks (1971), Jarvella (1971), and Sachs (1967) demonstrated that neither the structure nor the sentence complexity of prose was retained by the subject, although there was a remembering of the meaning of the material. Other investigators, such as Kintsch (1977), Snyder and Uranowitz (1978), and Sulin and Dooling (1974) found that their subjects' recall of prose reflected some change or reconstruction of the originally presented material, with such changes appearing to be generated by their subjects' previous knowledge of the topic, or by their stereotyped be- liefs. Spiro (1977) noted that when his subjects were presented with stories whose content contained some apparent contradictions, recall by these subjects reflected a reconciliation of the contradiction. Finally, the frequently quoted eyewitness testimony studies of Loftus and her associates (e.g., Loftus, 1974, 1975; Loftus, Miller, \& Burns, 1978; Loftus \& Palmer, 1974; Loftus \& Zanni, 1975) are also in keeping with the reconstruction hypothesis, since these investigators have noted that when their subjects were given information different from material that had been actually observed or presented on videotape, such additional information frequently resulted in changing the nature of the subjects' recall.

Note, then, that the general thrust of the selected studies we have cited provides some support for Bartlett's model of memory. But the reconstructive model of memory has also had its critics. Gauld and Stephenson (1967) and Gomulicki (1956) have pointed out methodological difficulties in Bartlett's (1932) research. And Neisser's $(1967,1982,1984)$ position that virtually all remembering is reconstructive or of a problem-solving nature has been regarded by many as patently false. Certainly an examination of many adult activities engaged in on a daily basis would suggest that the memorial representations involved are what Bahrick (1984) has identified as replicative (or reproductive) rather than reconstructive. As Bahrick (1984) has written, "there is no indication of reconstructive change in remembering one's name, the answer to simple arithmetic problems, the meanings of common words in our native language, and thousands of other overlearned facts, rules or meanings that constitute much of our general knowledge. These instances of literal recall are not the exception; they are the rule for overlearned memory content"' (p. 56). In summary, the findings that we have reviewed indicate that neither reproduction nor reconstruction provides a satisfactory description of verbal memory.

It is our contention that any examination of the kinds of memory operating with verbal materials should begin with a consideration of the type of recall demanded. Two types appear to play a prominent role: verbatim responding, and responding with the essence of the previously experienced material (commonly defined as gist).

Verbatim responding, from which we shall infer the construct of verbatim memory, is frequently found in our daily lives. Thus, the need to remember names or various combinations of numbers, along with a variety of facts and rules, is self-evident. It is apparent that Bartlett's hypothesized processes of abstraction and reconstruction have little relevance for an understanding of this type of memorial representation.

Responses that incorporate the main points or the essence of prose, from which we infer memory for gist, are also of major significance in our daily activities. The process of abstraction is inherent in any definition of gist, but it does not follow that gist will invariably include the operation of a reconstructive process. In fact, it is suggested that most often the remembered material is not 
reconstructive; rather, that which has been remembered agrees with or is congruent with material that was originally presented. The failure to include this type of remembering-what we have termed congruent abstraction-appears to be a significant omission in Bartlett and Neisser's conclusions concerning the nature of memory for prose. Since the experimental evidence that we have reviewed does, however, support the operation of a reconstructive process, we would describe such remembering, behaviorally, as incongruent abstraction. We do not believe, however, that the latter process makes the substantial contribution to verbal memory that Bartlett (1932) and Neisser (1967) have hypothesized.

The classification of verbal memory into the two major categories of verbatim and gist, with gist being subdivided into congruent and incongruent abstraction is in keeping with the general position adopted by many investigators who have posited that there is more than one type of memory (e.g., Cofer, 1973; Oakley, 1981; Ruggiero \& Flagg, 1976; Squire \& Cohen, 1984; Tulving, 1972, $1983,1984,1985)$. Whether or not the categories of verbal memories that we have identified actually differ remains an experimental question to be answered. One approach in examining this distinction would be to determine if verbatim memory and memory for gist are influenced in different ways by the manipulation of a particular experimental variable. There is the suggestion from the studies of Paivio and his associates (Paivio, 1965; Paivio, Smythe, \& Yuille, 1968; Paivio, Yuille, \& Rogers, 1969) and Marschark (1985) that such may be the case. Paivio and his associates have repeatedly found that concreteness (or word imagery) facilitates performance when lists of words are employed in paired associate and serial learning-tasks that demand verbatim recall. Marschark (1985) has noted, however, that differences in word imagery or concreteness found in a paragraph of prose did not influence recall performance. Obviously, more and better evidence is needed to establish the validity of the distinction that we have made among memory systems.

\section{REFERENCES}

Alba, J. W., \& Hasher, L. (1983). Is memory schematic? Psychological Bulletin, 93, 203-231.

BAHRICK, H. P. (1984). Replicative, constructive and reconstructive aspects of memory: I. Implication for human and animal research. Physiological Psychology, 12, 53-58.

BARTlett, F. C. (1932). Remembering: A study in experimental and social psychology. Cambridge, England: Cambridge University Press.

Bransford, J. D., \& Franks, J. J. (1971). The abstraction of linguistic ideas. Cognitive Psychology, 2, 331-359.

CoFer, C. (1973). Constructive processes in memory. American Scientist, 16, 537-543.

EbBINghaUs, H. (1913). Memory: A contribution to experimental psychology (H. A. Ruger \& C. E. Bussenius, Trans.). New York: Teachers College, Columbia University. (Original work published 1885)

Gauld, A., \& Stephenson, G. M. (1967). Some experiments relating to Bartlett's theory of remembering. British Journal of Psychology, 58, 39-49.
Gomulickı, B. R. (1956). Recall as an abstractive process. Acta Psychologica, 12, 77-94.

JARVELLA, R. J. (1971). Syntactic processing of connected speech. Journal of Verbal Learning \& Verbal Behavior, 10, 409-416.

JoHnson, R. E. (1970). Recall of prose as a function of the structural importance of the linguistic units. Journal of Verbal Leaming \& Verbal Behavior, 9, 12-20.

JoHNSON, R. E. (1974). Abstractive processes in the remembering of prose. Journal of Educational Psychology, 66, 772-779.

KINTSCH, W. (1977). Memory and cognition. New York: Wiley.

LofTUs, E. F. (1974). Reconstructing memory: The incredible eyewitness. Psychology Today, 8, 116-119.

LoFTus, E. F. (1975). Leading questions and the eyewitness report. Cognitive Psychology, 7, 560-572.

Loftus, E. F., Miller, D. G., \& BurNS, H. J. (1978). Semantic integration of verbal information into visual memory. Journal of Experimental Psychology: Human Learning \& Memory, 4, 19-31.

LOFTUS, E. F., \& PALMER, J. C. (1974). Reconstruction of automobile destruction: An example of the interaction between language and memory. Journal of Verbal Learning \& Verbal Behavior, 13, 585-589.

LofTUS, E. F., \& ZANNI, G. (1975). Eyewitness testimony: The influence of the wording of a question. Bulletin of the Psychonomic Society, 5, 86-88.

MARSCHARK, M. (1985). Imagery and organization in the recall of prose. Journal of Memory \& Language, 24, 734-745.

McGeOCH, J. A. (1933). Review of Bartlett's Remembering: A study of experimental and social psychology. Psychological Bulletin, 30, 774-776.

Meyer, B. J., \& MCConKIE, G. W. (1973). What is recalled after hearing a passage? Journal of Educational Psychology, 65, 109-117.

NeISSER, U. (1967). Cognitive psychology. New York: Appleton.

NeISSER, U. (1982). Memory observed: Remembering in natural contexts. San Francisco: W. H. Freeman.

NeISSER, U. (1984). Interpreting Harry Bahrick's discovery: What confers immunity against forgetting? Journal of Experimental Psychology: General, 113, 32-35.

OAKLEY, D. A. (1981). Brain mechanisms of mammalian memory. British Medical Bulletin, 37, 175-180.

PaIvio, A. (1965). Abstractness, imagery, and meaningfulness in paired associate learning. Journal of Verbal Learning \& Verbal Behavior, 4, 32-38.

Paivio, A., Smythe, P. C., \& Yuille, J. C. (1968). Imagery versus meaningfulness of nouns in paired-associate learning. Canadian Journal of Psychology, 22, 427-441.

Paivio, A., Yuille, J. C., \& Rogers, T. B. (1969). Noun imagery and meaningfulness in free recall and serial recall. Journal of Experimental Psychology, 79, 509-514.

RugGiero, F. T., \& FLAGG, S. F. (1976). Do animals have memory? In D. L. Medin, W. A. Roberts, \& R. T. Davis (Eds.), Process of animal memory. Hillsdale, NJ: Erlbaum.

Rummelhart, D. E. (1976). Understanding and summarizing brief stories. In D. LaBerge \& J. Samuels (Eds.), Basic processes in reading: Perception and comprehension. Hillsdale, NJ: Erlbaum.

SACHS, J. S. (1967). Recognition memory for syntactic and semantic aspects of connected discourse. Perception \& Psychophysics, 2, 437-442.

Schultz, E. E., JR., \& Johnson, R. E. (1982). Proactive effects in memory for stories. British Journal of Psychology, 73, 487-496.

SNYDER, M., \& URANOWITZ, S. W. (1978). Reconstructing the past: Some cognitive consequences of person perception. Journal of Personality \& Social Psychology, 36, 941-950.

SPIRO, R. J. (1977). Remembering information from text: Theoretical and empirical issues concering the "state of schema" reconstruction hypothesis. In R. C. Anderson, R. J. Spiro, \& W. E. Montague (Eds.), Schooling and the acquisition of knowledge. Hillsdale, NJ: Erlbaum. SQuire, L. R. , \& CoHEN, N. J. (1984). Human memory and amnesia. In G. Lynch, J. L. McGaugh, \& N. M. Weinberger (Eds.), The neurobiology of learning and memory. New York: Guilford Press.

Sulin, R. A., \& Dooling, D. J. (1974). Intrusion of a thematic idea 
in retention of prose. Journal of Experimental Psychology, 103, 255-262.

TUlviNG, E. (1972). Episodic and semantic memory. In E. Tulving $\&$ W. Donaldson (Eds.), Organization of memory. New York: Academic Press.

Tulving, E. (1983). Elements of episodic memory. New York: Oxford University Press.

Tulving, E. (1984). Multiple learning and memory systems. In K. M. J. Lagerspetz \& P. Niemi (Eds.), Psychology in the 1990's. Amsterdam: North-Holland.

Tulving, E. (1985). How many memory systems are there? American Psychologist, 40, 385-398.

Tulving, E., \& Madigan, S. A. (1970). Memory and verbal learning. In P. H. Mussen \& M. R. Rosenzweig (Eds.), Annual review of psychology. Palo Alto, CA: Annual Reviews.

WIENER, N. (1948). Cybernetics. New York: Wiley.

\section{NOTES}

1. Alba and Hasher (1983) have suggested that Bartlett's (1932) model provided a foundation that led some later investigators to posit what have been described as schema theories of memory. These theories have included the processes of abstraction and reconstruction, but they have also involved such processes as selection, interpretation, and integration. In this paper, however, we are primarily concerned with Bartlett's reconstruction model of memory and with later advocates of his position.

2 . The concept of repetition or reappearance needs to be more precisely defined. If reconstruction advocates mean that in order for a response to be repeated or to reappear, the response must be identical to the original in terms of form, magnitude, duration, direction, and so forth, it is unlikely that one response is ever repeated. It is likely, however, that most experimenters would consider such a definition of reappearance to be too restrictive. Thus, the activity of writing one's name on a blackboard is not the same as endorsing a check. But the signature would still be considered to be repeated or to reappear in the sense that the letters would be produced in the same order and that their form or shape in each instance would be very similar, although obviously differing in size.

(Manuscript received October 10, 1989.) 